\title{
Análise Microbiológica do Pescado Salgado e Seco Comercializado no Mercado Municipal de Cruz Das Almas, Bahia, Brasil
}

Rebeca Ayala Rosa da Silva (II,III), Brenda Borges Vieira (II), Carla Silva da Silveira (III), Elaine Araújo de Carvalho (II), Paulo Sérgio Pedroso Costa Júnior (II), Norma Suely Evangelista Barreto (II)

(II) UFRB - Universidade Federal do Recôncavo da Bahia (Rua Rui Barbosa, 710, Centro - Cruz das Almas - Bahia. CEP 44.380-000), (III) UFBA - Universidade Federal da Bahia ( Av. Adhemar de Barros, n 500, Ondina, Salvador - Bahia. CEP: 40.170-110.)

\section{Resumo}

O pescado é um alimento que possui importância nutricional devido o levado teor protéico, lipídios de boa qualidade e altos teores de vitaminas e minerais. O hábito de ingerir pescado varia conforme a região, sendo que a população utiliza as feiras livres e mercados municipais para adquirir o pescado em suas diversas formas de comercialização. No município de Cruz das Almas, Bahia, Brasil, o pescado salgado e seco é muito apreciado em virtude dos pratos típicos da região, como o acarajé e espetos de peixe seco, além do preço mais acessível. Devido à elevada suscetibilidade dos produtos da pesca, os processos de salga e secagem são métodos antigos e bastante utilizados na conservação do pescado, em virtude do baixo custo. A salga e a secagem são realizadas de acordo com o conhecimento popular, muitas vezes, sem o emprego das Boas Práticas de Manipulação e falhas higiênicossanitárias durante a comercialização. Estes fatores comprometem a inocuidade do produto final podendo estar envolvido em surtos alimentares. Baseado nisso, o presente trabalho objetivou avaliar a qualidade microbiológica do pescado salgado e seco comercializado em quatro boxes do mercado municipal de Cruz das Almas, Bahia, Brasil. Foram realizadas análises microbiológicas em 12 amostras de pescado salgado e seco, três amostras por estabelecimento, quanto à presença de

\footnotetext{
Referência:

Rebeca Ayala Rosa da Silva, Brenda Borges Vieira, Carla Silva da Silveira, Elaine Araújo de Carvalho, Paulo Sérgio Pedroso Costa Júnior, Norma Suely Evangelista Barreto. Análise Microbiológica do Pescado Salgado e Seco Comercializado no Mercado Municipal de Cruz Das Almas, Bahia, Brasil. In: Anais do 12 Congresso Latinoamericano de Microbiologia e Higiene de Alimentos - MICROAL 2014 [= Blucher Food Science Proceedings, num.1, vol.1]. São Paulo: Editora Blucher, 2014. DOI 10.5151/foodsci-microal-187
} 
coliformes a $45^{\circ} \mathrm{C}$, bactérias halofílicas e fungos filamentosos e leveduras. A presença de coliformes a $45^{\circ} \mathrm{C}$ variou de 6,5 x 106 UFC.g-1 est. e para os fungos filamentosos e leveduras de 6,5 x $106 \mathrm{UFC/g}$ est. A elevada carga microbiana de bactérias halofílicas e fungos filamentosos e leveduras no pescado salgado e seco indica falhas no processo de armazenamento e manipulação, principalmente porque os feirantes desconhecem as boas práticas de manipulação, evidenciando a perda de qualidade do produto devido alterações organolépticas que diminuirão o tempo de prateleira do alimento.

Palavras-Chave: Bactérias halofílicas, Coliformes a $45^{\circ} \mathrm{C}$, Pescado, Salga Agência de Fomento: 